ESTUDIOS

\title{
Disputas sobre el trabajo esclavo contemporáneo en Brasil y la precarización del sistema protector
}

\author{
Disputes over contemporary slave labor \\ in Brazil and the precarization of the protective system \\ Rafael Lamera Giesta Cabral (iD y Iury Alves de Sousa \\ Universidad Federal Rural del Semiárido, Brasil
}

\begin{abstract}
RESUMEN El artículo analizó las disputas conceptuales sobre la extensión del trabajo esclavo contemporáneo en Brasil para ilustrar la creciente tendencia abusiva que viola las directrices nacionales e internacionales sobre la protección del trabajo decente. Centrándose en el análisis de las controversias legislativas en el parlamento brasileño, llega a la conclusión de que las flexibilizaciones constitucionales sobre el concepto de trabajo esclavo contemporáneo amplifican la vulnerabilidad de los trabajadores dentro del sistema de protección.
\end{abstract}

PALABRAS CLAVE Trabajo esclavo, precaución laboral, sistema proteico.

ABSTRACT The article analyzed the conceptual disputes over the extent of contemporary slave labor in Brazil to illustrate the growing abusive trend that violates both national and international guidelines on the protection of decent work. Focusing on the analysis of legislative disputes in the Brazilian parliament, it concludes that constitutional flexibilizations on the concept of contemporary slave labor amplify the vulnerability of workers within the protective system.

KEYWORDS Slave labor, labor precaution, protective system.

\section{Introducción}

La naturaleza precaria de las relaciones laborales siempre ha estado en la agenda política de las organizaciones internacionales para la protección del trabajo decente. La Organización Internacional del Trabajo (OIT), que celebró su centenario en 2019, ha seguido de cerca el fenómeno que ahora se reconoce como «trabajo esclavo con- 
temporáneo». El término no sólo ha abarcado la restricción del trabajador a su lugar de trabajo, sin derecho a locomoción o a recibir un salario por el trabajo realizado, sino también la degradación de las condiciones de trabajo que afectan tanto al medio rural como al urbano.

Las acciones internacionales para liberar a los trabajadores textiles en Asia, Oceanía y América Latina se han convertido en algo habitual en las noticias. En Brasil, en pleno siglo XXI, no fue diferente: en la ciudad de São Paulo, con más de 20 millones de habitantes, los trabajadores bolivianos y haitianos, en condiciones análogas a la esclavitud, fueron liberados de numerosas industrias textiles nacionales. La comprensión del trabajo esclavo contemporáneo profundiza el análisis de las condiciones de trabajo precarias, prestando la debida atención a la explotación del esfuerzo humano en circunstancias degradantes, que son tan repugnantes como la práctica tradicional de esclavizar a las personas mediante el uso de la fuerza física y la coacción sobre la libertad de movimiento de las víctimas.

Pese el aumento de las violaciones del trabajo decente, el Brasil está experimentando un profundo movimiento de desregulación -o desconstitucionalización- de los derechos sociales que tienen un impacto directo en la protección laboral. Estas acciones, que ya han promovido cambios en los sistemas nacionales de trabajo y de seguridad social, se dirigen hacia la restricción del concepto de trabajo esclavo contemporáneo, a fin de limitar legalmente el instituto sólo a los casos en que se prohíbe al trabajador abandonar su lugar de trabajo.

El objetivo de esta investigación fue evaluar cómo estas disputas conceptuales, que flexibilizan el sistema de protección del trabajo decente, alteran los supuestos del constitucionalismo social brasileño, al incorporar métodos que convencionalmente llamamos constitucionalismo abusivo. A partir del análisis de los documentos legislativos producidos en el Congreso Nacional brasileño, buscamos investigar las narrativas, estrategias y límites de las disputas debatidas en el Parlamento. Con estos datos, identificamos las características del constitucionalismo abusivo episódico, que además de permitir la flexibilización de la protección de los derechos laborales, viola el sistema internacional.

Para alcanzar los objetivos enumerados, la investigación se basa en una metodología que incluye el razonamiento dialéctico, ya que el estudio que se desarrollará sobre la precariedad de las condiciones de trabajo en el Brasil partirá del supuesto de que el problema radica en la contradicción política que aborda las garantías sociales, que formulará el pensamiento a través de la lógica del conflicto político, fundamentando los argumentos que apoyarán la síntesis concluyente. Además, la técnica de la investigación bibliográfica se utiliza en conjunto con el estudio del análisis de las fuentes documentales para observar los cambios que se están produciendo en la política sobre los derechos de los trabajadores, sobre la base de diversos registros en la doctrina, la prensa y los documentos oficiales. 
Este artículo está organizado en tres etapas. La primera, se trata de presentar cómo se había logrado constitucionalmente la protección del trabajo decente desde la Constitución Federal de 1988, ${ }^{1}$ después de la dictadura militar brasileña (1964-1985). En la segunda etapa, se han articulado las características del constitucionalismo abusivo episódico en la fragmentación del modelo de constitucionalismo social. Por último, se ha demostrado cómo este movimiento allanó el camino para las disputas sobre el trabajo esclavo contemporáneo.

\section{El derecho fundamental al trabajo decente en el Estado democrático de derecho brasileño}

En la actualidad, el Estado democrático de derecho ha asumido un esquema formal que está plasmado en textos escritos, llamado Constitución. El concepto de la Constitución, así como la concepción del Estado, es variable y está influenciado por diversos factores históricos y culturales, lo que pone de manifiesto una dificultad en la delimitación precisa de las pautas constitucionales. Sin embargo, el modelo predominante en Occidente se basa en principios liberales, y se desarrolla con el propósito de restringir el poder de los monarcas mediante normas que preservan las libertades individuales.

Saldanha (2000: 20) entiende el Estado de derecho como la limitación de la acción del Estado a través de la Constitución, ponderando que el Estado de derecho «liberal burgués» es sólo uno de los varios modelos existentes, pero ésta es la base fundamental predominante en la historia contemporánea.

En la coyuntura de defensa del Estado de derecho se estableció la Constitución de la época contemporánea, que representa un instrumento político-jurídico respaldado por el Estado y al mismo tiempo le da validez, ya que establece restricciones que protegen, al menos en teoría, los intereses del pueblo. La Constitución, entonces, como señala Fioravanti (2001), consiste en la posibilidad de individualizar un límite legal al alcance de los poderes del soberano, ya que contradice a estos poderes una norma fundamental, que garantiza los derechos de los individuos.

Sin embargo, las constituciones con funciones que se limitan a garantizar los derechos de propiedad de las personas se han convertido en objeto de críticas, principalmente debido al empeoramiento de las desigualdades sociales y a las reflexiones sobre las violaciones de la dignidad humana de una gran parte de la población. En esta coyuntura, Delgado (2017) señala que, tras la devastadora experiencia de la Segunda Guerra Mundial, el surgimiento del modelo de Estado social basado en el Estado de derecho amplió la incorporación de los derechos sociales en las constituciones para

1. «Constituição da República Federativa do Brasil de 1988», Brasilia, 5 de octubre de 1988, disponible en https://bit.ly/2yNxXiV. 
integrar de forma permanente los principios de la dignidad humana y la justicia social en la experiencia contemporánea.

El carácter social se observa a través de la inserción de los derechos sociales en el cuerpo legislativo, con el objetivo de la efectividad de la igualdad material en la sociedad, mientras que el aspecto jurídico se defiende para el sometimiento de los gobernantes a la Constitución, con el fin de evitar el autoritarismo.

Este nuevo panorama representa una transfiguración del escenario sociopolítico, ya que, como detalló Carvalho Netto (1999), este movimiento no sólo se ocupó de las adiciones de los llamados derechos de segunda generación, sino también de la redefinición de los derechos individuales. La libertad comenzó a considerarse a través de la asunción de leyes sociales que hacen posible, al menos, el reconocimiento del lado social o económicamente más débil de la relación, internalizando en la legislación una igualdad tendencialmente material. Por lo tanto, los derechos sociales, centrados sobre todo en las garantías de los trabajadores, están ahora discriminados en las constituciones.

Siqueira, Spers y De Morais (2019) aclaran que el derecho al trabajo decente se inscribe en la segunda generación de los derechos humanos, y que es responsable de una producción de riqueza esencial para el desarrollo socioeconómico. Sin embargo, la mera afirmación de tales derechos no implica mejores condiciones de trabajo: se hace necesario un entorno propicio para la participación efectiva de los trabajadores en la lucha por sus derechos.

Al comentarse sobre el desarrollo histórico del concepto de Estado democrático de derecho, Da Silva (1992) explica que con el advenimiento de las transformaciones provocadas por el Estado liberal, el Estado social de derecho se convierte en un Estado de derecho material, al adoptar intentos de lograr la justicia social. ${ }^{2}$ Añadiendo que, salvo las inexactitudes del Estado social de derecho, el Estado democrático de derecho se caracteriza por ser un concepto nuevo, en el que la Constitución brasileña vigente abre perspectivas de profunda realización social mediante la práctica de los derechos sociales que inscribe, basados en la dignidad de la persona humana.

El elemento democrático de este concepto debe ser reflejado. Carvalho Netto (2001: 70) ya advirtió que «la democracia es una de esas palabras que en nuestra vida cotidiana consideramos obvias y, precisamente por serlo, terminamos por no problematizarla, suponiendo que todos atribuimos naturalmente a esta palabra el mismo contenido semántico».

Frente a esto, la idea de un Estado democrático no puede ser confortada sólo por el cumplimiento de la voluntad de las mayorías, porque la democracia expresa el deseo de representar el pluralismo social existente.

2. En Brasil, la protección laboral ha sido fuertemente promovida desde la década de 1930. Para más detalles, véase França y Cabral (2016). 
La representación de los deseos de los grupos vulnerables debe salvaguardarse tanto por razones humanitarias, al tratar de mejorar la calidad de vida de las personas, como por razones pragmáticas, al establecer condiciones que no hagan peligrar la estabilidad del sistema actual.

Delgado y Delgado (2012) sostienen que en esta trayectoria histórica surge el fenómeno de la constitucionalización de los derechos sociales, y el derecho laboral está ahora incorporado por varias constituciones. Es importante señalar que el Estado democrático de derecho es el más avanzado en el respeto de los derechos humanos, mediante la consideración de la dignidad humana como base que guía todos los derechos fundamentales.

El análisis de la coyuntura internacional también refuerza la relevancia del respeto al trabajo decente. En las organizaciones de las que Brasil es signatario, se destacan las siguientes: el párrafo 1 del artículo 23 de la Declaración Universal de Derechos establece que «toda persona tiene derecho al trabajo, a elegir libremente su trabajo, a condiciones equitativas y satisfactorias de trabajo y a la protección contra el desempleo»; y el artículo 6 del Protocolo Adicional al Pacto de San José de Costa Rica establece que «toda persona tiene derecho al trabajo, que comprende la posibilidad de obtener los medios para llevar una vida digna y decorosa mediante el desempeño de una actividad lícita, libremente elegida o aceptada».

Cabe señalar que la práctica de la explotación humana mediante la esclavitud es la forma más perjudicial de violación del principio del trabajo decente. Jara Bustos (2016) refuerza que la esclavitud y los trabajos forzados causan una lucha universal, ya que niegan la libertad humana más básica, al transformar al ser humano en un mero instrumento de los deseos de los demás. En conformidad con lo anterior, la Organización Internacional del Trabajo ha ampliado su acción, con el fin de salvaguardar los intereses de los trabajadores y, en consecuencia, promover la atención mundial a la cuestión del trabajo esclavo. Según Borges (2015), la eliminación de todas las formas de trabajo forzoso es un principio de la OIT relativo a los derechos fundamentales de los trabajadores, previsto desde su fundación y con la aceptación obligatoria de los países firmantes.

Desde el punto de vista material, el preámbulo de la Constitución de la OIT hace hincapié en que la justicia social debe ser la base para la visualización de una paz duradera y universal. Por lo tanto, es necesario emitir normas que representen este deseo.

Bajo lo expuesto, la OIT promulgó el Convenio 29, en 1930, y el Convenio 105, en 1957, con el propósito de establecer las directrices para la abolición del trabajo forzoso en todas sus especies. Con el enfoque en la mayor efectividad de estas regulaciones, Machado (2017) aclara que la OIT adoptó dos nuevos instrumentos sobre el trabajo forzoso: el Protocolo que complementa la Convención 29, de 1930, sobre el trabajo forzoso, y una Recomendación que proporciona directrices sobre la aplicación del mencionado Protocolo. 
Esas disposiciones refuerzan el derecho internacional vigente, como observó Machado (2017), relacionando las iniciativas recientes con las directrices propugnadas en la Convención de las Naciones Unidas sobre la Esclavitud de 1926, la Convención suplementaria sobre la abolición de la esclavitud, la trata de esclavos y las instituciones y prácticas análogas a la esclavitud de 1956, y el Protocolo adicional de la Convención de las Naciones Unidas contra la Delincuencia Organizada Transnacional relativo a la prevención, la represión y el castigo de la trata de personas, especialmente mujeres y niños, de 2003.

En el ámbito regional, los países americanos también se han movilizado para establecer compromisos de erradicación de todas las formas de esclavitud. Destaca la Convención Americana sobre Derechos Humanos de 1969, que refuerza la prohibición de la esclavitud en su artículo 6. Es importante señalar que Brasil es su respectivo signatario desde el 6 de noviembre de 1992.

Por lo tanto, como resume Machado (2017), la eliminación del trabajo forzoso es un principio central del derecho internacional y de los derechos humanos. En vista de lo que se evidencia, la Constitución brasileña de 1988, en armonía con el logro del Estado democrático de derecho, destaca la importancia de la dignidad humana. Esta premisa queda ilustrada por el punto 3 del artículo 1, que destaca la dignidad de la persona humana como fundamento de la República; el artículo 5, que garantiza la igualdad y las garantías de todos por el mero hecho del carácter humano; el artículo 193, que destaca que el orden social se basa en la primacía del trabajo y tiene por objeto el bienestar y la justicia social; y el artículo 170, que subraya que el orden económico debe asegurar a todos una existencia digna.

En este sentido, Delgado y Delgado (2018) destacan tres pilares de apoyo a la Constitución Federal: la arquitectura constitucional de un Estado democrático basado en el Estado de derecho, los principios humanísticos y sociales, y la concepción constitucional de los derechos humanos fundamentales, afirmando que los principios laborales constitucionales establecen los límites y las fronteras de las normas jurídicas infraconstitucionales en Brasil. Por lo tanto, el carácter protector del derecho laboral para apoyar el vínculo hiposuficiente de las relaciones laborales, el trabajador, se sustenta en la esencia misma de la Constitución brasileña y los tratados internacionales de los que Brasil es signatario. En vista de ello, cualquier violación a la dignidad del empleado enfrenta toda la estructura principista que sostiene el Estado democrático de derecho.

Por consiguiente, Delgado y Borges (2015) indican que la contribución del constitucionalismo de 1988 radica en garantizar un proyecto de apoyo inclusivo, incluyendo en las relaciones laborales una perspectiva que no se centra exclusivamente en los derechos de propiedad contractual, sino también en los derechos contractuales fuera de balance, basados en la directriz del principio de protección. Dicho esto, el Estado debe asumir el compromiso de elaborar un microsistema jurídico que satisfaga los 
intereses del trabajador para mitigar el desequilibrio inherente a los contratos de trabajo y, además, desarrollar estrategias políticas que busquen hacer efectivas las garantías de los empleados durante un proceso político que evite ataques a los lineamientos constitucionales para la preservación de la dignidad humana.

Souto Maior (2017), por ejemplo, resume que el trabajo es de la esencia humana, en el sentido del deber de apreciación personal e integración social, poe lo que es un deber y un derecho en la relación del individuo con la sociedad y el Estado. Añade que el derecho laboral debe basarse en el respeto a la esencia de la obra, en vista de los criterios éticos que son inherentes debido a las directrices constitucionales actuales. Así, el derecho al trabajo decente es un fundamento inseparable del Estado democrático de derecho, que representa una adaptación constitucional a los deseos de la población, preservando el principio de la dignidad humana en las relaciones laborales, a fin de salvaguardar las garantías humanas de los sujetos que se encuentran en el eslabón hiposuficiente de la producción.

Por lo tanto, en lo que respecta a la jerarquía constitucional que sustenta la seguridad jurídica necesaria para el desarrollo socioeconómico, las relaciones laborales, junto con todos los aspectos que ellas implican, serán consideradas como medios para el logro de la dignidad de todos los sujetos implicados, respetando los lineamientos constitucionales que sustentan el ordenamiento jurídico del país. Sin embargo, el análisis de la realidad implica la percepción de que la prevalencia teórica de las normas constitucionales no está debidamente establecida en la vida social cotidiana, sobre todo en relación con los derechos de los trabajadores, ya que están directamente influenciados por intereses económicos y políticos que no tienen en cuenta los derechos laborales garantizados.

En vista de lo anterior, es necesario observar la Constitución, no sólo por sus directrices expuestas, sino también desde el punto de vista del análisis crítico de si las fuerzas políticas y sociales están actuando de conformidad con las disposiciones de la legislación. Por ello, los siguientes debates sobre la forma de medir esas violaciones constitucionales son importantes, a fin de establecer instrumentos eficaces para salvaguardar los derechos ya conquistados que se expresan en la Constitución.

\section{Tensiones en el constitucionalismo social brasileño y la perspectiva de un constitucionalismo abusivo}

La protección social prevista en la Constitución de 1988 siempre se ha considerado pionera en el proceso de reconstitución del país tras una dictadura cívico-militar de 21 años. Esto no significa que las controversias extensas o restrictivas sobre el alcance de esta protección laboral se hayan neutralizado después del texto constitucional. Los argumentos de que la Constitución de 1988 sería irrealizable debido a la extensión de los derechos, incompatible con el desarrollo económico del país, siempre han acom- 
pañado a las justificaciones de la violación de esta protección. Los intentos de reformar el texto constitucional con el fin de promover una reducción de los derechos y garantías fundamentales también se pusieron a prueba en el Parlamento brasileño, a través de las enmiendas propuestas a la Constitución.

Las crisis económicas y políticas, por otra parte, se han vuelto más eficaces para justificar las acciones de desconstitucionalización de derechos. El discurso económico acaba sin problemas creando un ambiente de adhesión de los empresarios y de la sociedad en general que, dada la desigualdad social en aumento, busca medidas mediáticas que sustituyan al debate público. Así, el movimiento reformista, aislado del debate público e inmerso en el discurso económico que tiene su propio lenguaje, promueve tensiones en el constitucionalismo social. Esto se debe a que el Estado democrático de derecho se caracteriza por la valorización de un sistema jurídico que promueve la democracia en los aspectos sociales y políticos, mediante la garantía de los derechos humanos, imponiendo una restricción al Estado para proteger a los individuos del poder de los gobernantes y también de las influencias de las clases sociales dominantes.

En esta perspectiva, destacan las enmiendas constitucionales aprobadas después del proceso político que culminó con el juicio político de la presidenta Dilma Rousseff (Partido de los Trabajadores), para jurar su vicepresidente, Michel Temer (Movimiento Democrático Brasileño), como líder del Poder Ejecutivo.

La Enmienda Constitucional 95, de 2016, ${ }^{3}$ instituyó un nuevo régimen fiscal que estableció un límite máximo para el gasto público. La principal característica del concepto implementado es que los gastos, incluidos los de las inversiones públicas, se congelarán en el parámetro de gasto del año de la implementación de este modelo fiscal hasta los próximos veinte años financieros. La aprobación de esta enmienda constitucional legitima parte del discurso político que defiende que la crisis económica proviene del gasto público de interés social. Este entorno político dificulta la financiación necesaria para cumplir el objetivo constitucional de reducir las desigualdades, además de restringir la efectividad de los derechos sociales enumerados en el artículo 6 de la Constitución, que exigen políticas afirmativas para garantizarlos.

Otro cambio impactante fue la Enmienda Constitucional 103, de 2019, ${ }^{4}$ que cambió el sistema de seguridad social. Incluso frente a la premisa constitucional implícita que impide la regresión social, basada en los fundamentos de la dignidad humana y el valor social del trabajo, y a la directriz constitucional de expansión de los derechos

3. Emenda Constitucional 95, del 15 de diciembre de 2016, «Altera o ato das disposições constitucionais transitórias, para instituir o novo regime fiscal, e dá outras providências», disponible en https://bit. ly/2GnhhT8.

4. Emenda Constitucional 103, del 12 de noviembre de 2019, «Altera o sistema de previdência social e estabelece regras de transição e disposições transitórias», disponible en https://bit.ly/3814G3j. 
fundamentales, el derecho social expreso a la asistencia social fue cuestionado de manera significativa.

La reforma cambió el derecho a la jubilación por tiempo de contribución, con un límite mínimo de 65 años para los hombres y 62 años para las mujeres para reclamar el beneficio y el requisito de cotizar a los trabajadores regulares. Con estos cambios, el trabajador solo tendría derecho a percibir el $100 \%$ del salario medio que aportó si tuviera 40 años de cotización a la seguridad social (o 35 años para las mujeres). Es importante señalar que la idea original de la propuesta, luego rechazada en el Congreso Nacional, era afectar también el derecho al bienestar de los trabajadores rurales, para someterlo a la lógica de concesión del trabajador regular, lo que prácticamente aniquilaría la efectividad del derecho al bienestar de esta clase, debido a la menor esperanza de vida por la prestación de servicios en tan arduos trabajos.

Las constantes reformas que generan la desconstitucionalización de los derechos afectan al modelo de constitucionalismo social y pueden ser entendidas dentro de parámetros más extremos, como el configurado por el constitucionalismo abusivo. Barboza y Robl Filho (2018) refuerzan que, en el contexto del constitucionalismo, hay límites en sus directrices, consistentes en un marco supralegal en la conformación del uso de los instrumentos y técnicas constitucionales propiamente dichos por los poderes constituyentes reformadores, e incluso por los originales, que son: la separación de poderes, la garantía y promoción del núcleo esencial de los derechos fundamentales y los institutos de la democracia pluralista. Sin embargo, Barboza y Robl Filho (2018) advierten que la utilización de los instrumentos previstos en el derecho constitucional positivo suele camuflar la violación de la estructura de las democracias constitucionales.

Dicho esto, es necesaria una reflexión profunda por parte de los estudiosos del derecho, junto con las instituciones sociales y políticas, sobre los temas tratados en los procesos legislativos y las políticas públicas, que se idealizan para analizar si tales iniciativas son conformes a la Constitución, ya que el mero uso de los instrumentos constitucionales no garantiza el respeto de sus directrices.

Esta coyuntura mejora la visualización de los nuevos modelos autoritarios, aunque disfrazados de legalidad constitucional. En vista de ello, Landau (2013) presenta el concepto de constitucionalismo abusivo, caracterizándolo como el uso indebido de los institutos de Derecho Constitucional y del Estado Constitucional para enfrentar la democracia, ayudando en la implementación de aspectos de autoritarismo sin necesidad de rupturas drásticas en la dinámica estructural del Estado.

Cabe destacar que el uso de este concepto de constitucionalismo abusivo pone de manifiesto el problema de una práctica que utiliza la legitimidad de las constituciones, por lo que su carácter se sustenta en acciones que, bajo el camuflaje del texto constitucional, indican a la sociedad un supuesto respeto al orden vigente a través del discurso de aceptación de formas y fundamentos constitucionales. 
El fenómeno del constitucionalismo abusivo se caracteriza por el uso de técnicas constitucionales que violan la Constitución de una manera menos notoria, ya que no implican la necesidad de golpes institucionalizados y violentos para romper con el sistema legal establecido. Fachin (2013) ayuda a desarrollar el concepto argumentando que el ejercicio del poder no puede ser ilimitado para evitar su ejecución extrema, que estaría más allá de las fronteras de la propia coexistencia comunitaria. El autor también destaca que el abuso consiste precisamente en la violación de las normas que engendran la llamada supralegalidad.

Por ello, el concepto abordado es adecuado para la explicación ardua de un escenario tenso de democracia y autoritarismo bajo el dominio de una constitución, ya que aclara la posición de que la democracia trasciende el mantenimiento de la participación mayoritaria en la elección de los respectivos gobernantes, con énfasis en que es necesario defender los mecanismos de control entre los poderes representativos, influenciados por una continua vigilancia de los movimientos sociales sobre los derechos sustentados en los fundamentos de la Constitución.

La inserción de la perspectiva autoritaria en un sistema constitucional, precisamente cuando prevalece este aspecto abusivo indicado, fundamenta la premisa expuesta en el concepto resaltado, cuando los medios democráticos y constitucionales protegen, desde el punto de vista formal, un sistema de gobierno que sacude, de manera encubierta, las estructuras de la democracia y la Constitución para una perpetuación del poder asociada al mantenimiento de un plan económico o político disociado de las garantías constitucionales.

El concepto de constitucionalismo abusivo, aunque ya utilizado por la literatura jurídica desde hace algunos años, no siempre puede utilizarse para todos los países. En vista de este concepto, Barboza y Robl Filho (2018) detallan que hay dos especies principales que ilustran el constitucionalismo abusivo: el número exagerado de enmiendas a la Constitución y las nuevas normas constitucionales con el fin de perpetuar un grupo político en el poder sacrificando los principios democráticos constitucionales, lo que representa un constitucionalismo abusivo estructural; y el uso de medios previstos en la Constitución en desacuerdo con las directrices de la democracia constitucional, que identifican como constitucionalismo episódico.

En Brasil no se visualiza el estado avanzado del constitucionalismo estructural abusivo, ya que se percibe, en cierta medida, la preservación de las instituciones democráticas en el deseo de salvaguardar el sistema de contrapesos necesario para la armonización del entorno democrático. Sin embargo, hay pruebas constantes de la identificación del Brasil con el abuso constitucional episódico, en el que se visualiza una tendencia política, que ya se refleja en la legislación, a confrontar las directrices constitucionales para la preservación de los derechos individuales, en especial los derechos sociales. Las controversias sobre el concepto de trabajo esclavo contemporáneo son un ejemplo de este movimiento y se abordarán en la próxima sección. 
La desconstitucionalización de los derechos llevada a cabo por las asambleas ordinarias, sin poderes constituyentes, es una medida de extrema preocupación para el sistema jurídico. El cambio constitucional, bajo el sello de las normas de revisión constitucional, con sus procedimientos legislativos, puede ser incluso legítimo en un primer momento, pero también puede coquetear con el abuso de las normas del constitucionalismo.

Esa situación es aún más preocupante en Brasil, debido a un sistema político que sobrevalora la figura del presidente de la República, formando en el imaginario social -incluso a causa de la historia autoritaria de los regímenes políticos brasileños- la percepción errónea de que el jefe del Poder Ejecutivo tiene poderes capaces de llevar a cabo cualquier medida deseada por la mayor parte de la sociedad, aunque sea en detrimento del sacrificio de los derechos de los grupos vulnerables, sin tener en cuenta ningún límite legal o de evaluación.

Desde esta perspectiva, Barboza y Robl Filho (2018) advierten que la ampliación de los mecanismos de control no altera el problema central de la relación entre los poderes en el hiperpresidencialismo, porque en momentos de gran estabilidad política, el presidente incorpora un apoyo popular exacerbado que restringe la capacidad de control de sus acciones, mientras que en momentos de crisis política, se produce un debilitamiento concentrado en la Presidencia de la República, lo que conlleva la posibilidad de un abuso de poder por parte del Parlamento a la hora de redactar normas que se enfrenten a los intereses del Ejecutivo.

En este escenario, la relevancia del Poder Judicial — sobre todo de la Corte Suprema- aumenta, porque es, en teoría, el guardián de la Constitución, en su acción precisa para combatir los abusos inconstitucionales derivados del uso indebido de los instrumentos previstos por la ley. Tushnet (2013) subraya que el Tribunal Supremo tiene la función de analizar el marco de la ley, tanto en los aspectos formales como en el mérito, para observar si hay alguna violación de la ley protegida por la Constitución, lo que representa una perfecta analogía con la realidad brasileña también.

Dicho esto, la teoría del constitucionalismo abusivo demuestra, como sostienen Barboza y Robl Filho (2018: 87), que las estructuras del Estado constitucional y los instrumentos constitucionales, como las enmiendas constitucionales y el proceso legislativo constitucional, pueden utilizarse de manera abusiva. Se demuestra la pertinencia de la existencia de una categoría de dogma constitucional capaz de evaluar la eficacia de la base filosófica del constitucionalismo democrático. Los aspectos negativos del constitucionalismo abusivo son aún más perjudiciales para los grupos que se encuentran en una etapa vulnerable, ya que la falta de representatividad política lleva a una supresión mayor de sus garantías, bajo el agravante de la omisión de las instituciones democráticas, lo que pone de relieve una afrenta perjudicial a los principios básicos de la Constitución. 
La vulnerabilidad de los trabajadores explotados por la esclavitud contemporánea ilustra una situación degradante de violaciones del actual régimen constitucional de protección, como se examinará en el próximo capítulo. El concepto de constitucionalismo abusivo, bajo el panorama del trabajo esclavo contemporáneo, expone una serie de medidas políticas que violan las instrucciones constitucionales, con el agravante de afectar a personas con necesidades latentes y en situaciones difíciles de cambios de vida. Por lo tanto, tiene la intención de abordar los medios por los que los agentes políticos se enfrentan a las bases constitucionales mediante acciones que impulsan el constitucionalismo abusivo, y cómo tales medidas acentúan las condiciones indignas $-\mathrm{y}$ por lo tanto inconstitucionales- de una parte relevante de la clase obrera brasileña.

\section{Trabajo esclavo contemporáneo: Disputas conceptuales y el debate nacional}

La práctica del constitucionalismo abusivo en Brasil afecta gravemente a la clase obrera, ya que los intereses de las clases dominantes se enfrentan a las directrices del Estado democrático de derecho para privilegiar sus aspiraciones por encima de las garantías de los trabajadores. El sistema de justicia brasileño, como se ha demostrado en los capítulos anteriores, preserva la dignidad humana junto con el valor social del trabajo como las bases principistas que deben guiar todas las regulaciones que afec$\tan$ a los contratos de trabajo.

Sin embargo, existe una creciente tendencia respecto de las pautas constitucionales a través de constantes proyectos de ley o actos del Ejecutivo para flexibilizar o incluso desregular las normas reguladoras del trabajo, lo que hace más precarias las condiciones de los sujetos en etapas vulnerables. Esto ha ocurrido bajo la justificación de un supuesto crecimiento económico que sólo beneficia a un grupo minoritario, el cual, a través de la acumulación de riqueza, obtiene representación política para utilizar los instrumentos constitucionales con el fin de violar la propia Constitución democrática y los derechos.

De la mano de obra, se destaca la deplorable situación del trabajo esclavo contemporáneo en Brasil. Según el sitio web Global Slavery Index, ${ }^{5}$ en 2016, aproximadamente 369.000 personas sufrieron en condiciones análogas a la esclavitud en Brasil, es decir, 1,8 personas sometidas están a esta realidad por cada mil personas. El tra-

5. El Índice Mundial de Esclavitud es una clasificación anual de las condiciones de esclavitud en los países de todo el mundo, publicada por la Walk Free Foundation (organización internacional independiente de derechos humanos). Se basa en una medición combinada de tres factores: i) una estimación de la prevalencia de la esclavitud moderna por población; ii) una medición del matrimonio infantil; y iii) una medición de la trata de personas dentro y fuera del país. Disponible en https://www.globalslaveryindex.org/. 
bajo esclavo contemporáneo, definido en el artículo 149 del Código Penal brasileño (1940), es la reducción de alguien a una condición análoga a la de esclavo, ya sea sometiéndolo a trabajo forzoso o a una jornada de trabajo exhaustiva, ya sea sometiéndolo a condiciones de trabajo degradantes, ya sea restringiendo, por cualquier medio, su locomoción, debido a una deuda contraída con su empleador o patrono.

En esta percepción, hay una superación del concepto tradicional de esclavitud en Brasil, que caracterizaba el trabajo esclavo a través de la visualización de la coacción física que restringía la libertad de locomoción del trabajador. El nuevo concepto presentado en la legislación brasileña amplía la interpretación a fin de salvaguardar los derechos de las personas que se encuentran en condiciones altamente degradantes.

Gomes y Guimarães Neto (2018) sostienen que la designación «trabajo esclavo contemporáneo» debe considerarse no como resultado de una simplificación o distorsión de los significados, sino como una poderosa metáfora que moviliza el pasado, comprende el presente y defiende un futuro en el que los trabajadores sean hombres libres con derechos protegidos por el Estado y garantizados por la ley.

El trabajo esclavo contemporáneo somete a sus víctimas a condiciones que las excluyen de cualquier concepción que exprese el principio de la dignidad de la persona humana, incluso si ésta representa la base del Estado democrático según la legislación brasileña. Vilela (2006) sostiene que la esclavitud contemporánea, en ciertos aspectos, es peor que la esclavitud «clásica», porque el trabajador esclavo de hoy, con cierta abundancia de mano de obra, es desechable. No tiene ningún valor económico, ningún valor de mercado, como el esclavo negro tenía, considerando que el amo de los esclavos tenía que tomar algunas medidas para mantener al esclavo vivo y sano. No es el esclavo de hoy, por completo reemplazable.

Con este enfoque, la vulnerabilidad de las personas sometidas a condiciones análogas a la esclavitud ilustra el obstáculo que plantea esa práctica, al considerar el derecho al trabajo decente como la base del sistema jurídico del país, debido a la falta total de circunstancias adecuadas para que los sujetos de la producción se desarrollen desde una perspectiva materialmente humana.

La forma más común de este tipo de esclavitud en Brasil es la explotación de la vulnerabilidad de las personas que se encuentran en situaciones de total abandono y en un estado de desesperación para lograr algo mejor para ellos y sus familias. Los reclutadores prometen ofertas de trabajo regulares con buena remuneración, pero lejos de la convivencia social de los trabajadores, quienes aceptan con la confianza de que obtendrán recursos para volver a su tierra en condiciones más ventajosas.

Mientras tanto, en su camino al lugar de trabajo, los explotados ya incurren en deudas para pagar el transporte, la comida y el mantenimiento de las necesidades básicas. Estas pendencias se vuelven imposibles de pagar, debido a la baja remuneración recibida y a la falta de apoyo humano para la subsistencia de los trabajadores. 
Gomes y Guimarães Neto (2018: 122) demuestran el testimonio del trabajador Josenildo, que fue explotado en las actividades mineras de Rondônia, informando lo siguiente:

No era lo que soy hoy. Ya lo hice, ¿no? Porque esta vida que estaba llevando allí... Trabajar un día... en un lugar; otro día en otro. Eso no verá nada allí. Terminas muriendo. Y mueres sin ningún lugar donde caer. Porque el tipo no construye nada. Lo que gana en una granja o en un garimpo, ya lo gasta viajando a otro lugar o incluso si no viaja. Pero cuando llega a la ciudad, todo explota. ¡Nada se queda!

En este escenario, el trabajador queda marginado de la convivencia social, sacrificando su propia esencia como ciudadano, por lo que queda impedido de cualquier forma de participación política o económica. Por esto, la lucha contra el trabajo esclavo contemporáneo es un deber social, económico y humanitario, ya que trata de reprimir una práctica socialmente repulsiva, económicamente inviable para el desarrollo y que provoca la ruptura de los lazos familiares y la pérdida responsable de la dignidad individual.

Cabe señalar que este desolador escenario no es una preocupación exclusiva del Brasil, ya que también refleja las circunstancias de los países vecinos, lo que tiende a agravar aún más los males sociales brasileños, al atraer a esos trabajadores latinos que se encuentran en situaciones vulnerables. En este panorama, Borges (2015) advierte que las violaciones de los derechos humanos en América Latina están sujetas a los intereses del mercado, con la triste tendencia a reducir a las personas a condiciones análogas a la esclavitud, enfrentando la dignidad de los trabajadores y los innumerables derechos sociales que se protegen en las constituciones de cada país.

Sobrinho, Da Silva Barros y Marques (2014) ilustran la posición mencionada cuando señalan que alrededor de 12.000 bolivianos están sometidos a condiciones análogas a la esclavitud, entre la ya alarmante estimación de 70.000 bolivianos que trabajaban de manera irregular en la industria textil sólo en la ciudad de São Paulo en 2006. Por consiguiente, el Estado brasileño debería aumentar sus esfuerzos y asignar recursos adecuados a los organismos que supervisan la lucha contra el trabajo esclavo, además de promover políticas públicas educativas de prevención y cumplir su función punitiva determinando sanciones ejemplares para los infractores que explotan el trabajo de otros en condiciones indignas.

Sin embargo, la realidad demuestra el logro del fenómeno del constitucionalismo abusivo en relación con el trabajo esclavo contemporáneo, ya que se observan constantes iniciativas que indican una clara afrenta a las bases constitucionales del Estado brasileño, ya que atacan el carácter de garantía de las relaciones laborales y tratan de aumentar aún más la explotación del trabajador con medidas que mitigan la lucha contra el trabajo esclavo contemporáneo. 
En relación con la esclavitud contemporánea en Brasil, se observa que el constitucionalismo abusivo se manifiesta de forma indirecta, porque su expresión es sobre todo a través de normas infraconstitucionales como leyes, ordenanzas y enmiendas a las legislaciones ordinarias; pero no es menos impactante, ya que esas normas son las que se refieren de manera específica a las relaciones laborales y alcanzan la concepción de trabajo análogo al de la esclavitud.

A modo de ejemplo, la Enmienda Constitucional 81, de 2014, ${ }^{6}$ supuso un gran avance en la lucha contra el trabajo esclavo, por la disposición de la confiscación de las propiedades rurales o urbanas en las que la explotación del trabajo esclavo se encuentra en forma de ley, sin ninguna compensación al propietario y sin perjuicio de otras sanciones previstas. Sin embargo, como resultado de una fuerte presión política sin respaldo constitucional, esta norma, que fue idealizada en 2001, sólo fue aprobada trece años después y aun así entró en el sistema con una eficacia limitada, es decir, se necesita una ley infraconstitucional para regular esta sanción para los propietarios que someten a los trabajadores a condiciones análogas a la esclavitud. Por lo tanto, la norma, con el objetivo de hacer efectivas las directrices constitucionales en materia de garantías sociales, sólo podía publicarse después de la maniobra política de publicar una ley que no pudiera aplicarse.

Esto se agrava por la propuesta enviada al Senado Federal brasileño por el senador Romero Jucá (Partido del Movimiento Democrático, PMDB) quien, bajo la máscara de la legalidad constitucional, presentó el proyecto de ley 432, de 2013. ${ }^{7}$ El proyecto de ley tenía por objeto regular la expropiación de tierras de los propietarios que serían castigados por los tribunales por mantener a los trabajadores en condiciones análogas a la esclavitud. En la disputa conceptual que afectaría a las acciones del Gobierno para combatir el trabajo esclavo contemporáneo, el proyecto de ley buscaba restaurar la interpretación del crimen limitando el trabajo esclavo a las amenazas físicas y restringiendo la libertad de los trabajadores para ir y venir.

Esta acción, propuesta por el proyecto de ley, tendría como resultado la desprotección legal de miles de trabajadores que se ven sometidos cada día a trabajos forzados, a jornadas exhaustivas de trabajo y a condiciones degradantes sin que necesariamente tengan limitaciones físicas en sus cuerpos, ya que la propia coyuntura que se les impone es ya el principal factor de coacción. Se observa el esfuerzo reiterado de considerables fuerzas políticas en sacudir los principios constitucionales mediante constantes ataques, disimulados por los instrumentos procesales legales, contra la

6. Emenda Constitucional 81, de mayo de 2014, «Dá nova redação ao art. 243 da Constituição Federal», disponible en https://bit.ly/323GUjq.

7. Proyecto de ley 432, de 2013, «Dispõe sobre a expropriação das propriedades rurais e urbanas onde se localizem a exploração de trabalho escravo e dá outras providências», disponible en https://bit. ly/3p4pI7d. 
principal norma vigente que propone un mecanismo para combatir el trabajo esclavo contemporáneo.

Esta posición recibe un apoyo político considerable, que puede verse en varios proyectos de ley o enmiendas legislativas. Por ejemplo, el proyecto de ley del Senado 236, de 2012, propuesto por el senador Blairo Maggi (Partido Liberal, PL/MT), ${ }^{8}$ aboga por la supresión de las condiciones degradantes y los días exhaustivos de prescripción penal. Se afirma que tal ajuste es necesario para que el mero incumplimiento de la legislación laboral no sea entendido como un delito por los inspectores de las condiciones de trabajo.

El concepto previsto en el Código Penal también está siendo confrontado por el Poder Ejecutivo, desde que Michel Temer tomó posesión de su cargo. En octubre de 2017 se publicó la Ordenanza 1.129. ${ }^{9}$ Con el fin de regular la concesión de las prestaciones del seguro de desempleo a los trabajadores víctimas de la reducción a una condición análoga a la de la esclavitud, la Ordenanza menciona, en su artículo 1, las percepciones coherentes sobre las condiciones degradantes y el horario de trabajo exhaustivo; sin embargo, esos factores no entran en el concepto de trabajo análogo al de la esclavitud. Esa caracterización se hace aún más restringida al imponer la necesidad de utilizar armas para retener al trabajador en el lugar de trabajo, ignorando todas las demás circunstancias que restringen la libertad de las víctimas.

La Ordenanza 1.129 sólo restringe el concepto a la privación de libertad, lo cual es inadecuado para el contexto histórico del siglo XXI. Esta pretensión considera que las condiciones de los trabajadores se convirtieron en accesorias y no principales para la definición del delito de trabajo análogo al de la esclavitud, satisfaciendo los intereses de los que se benefician de la explotación del trabajo precario.

La circunstancia política de la Ordenanza 1.129 refuerza esta hipótesis. Gomes y Guimarães Neto (2018) anuncian que esto ha sido publicado como resultado de un acuerdo entre el presidente Michel Temer y la correspondiente bancada ruralista de la Cámara de Diputados, que ya tenía un representante como ministro de Agricultura. Según la prensa de la época, el debilitamiento de la lucha contra la esclavitud contemporánea fue utilizado como moneda de cambio para el apoyo de los campesinos en la protección del presidente ante la segunda acusación de corrupción que sufría.

El análisis sobre el constitucionalismo abusivo en Brasil en relación con los derechos sociales involucra no sólo la percepción de la acción de las fuerzas políticas en el

8. Proyecto de ley del Senado 236, de 2012, «Reforma do Código Penal brasileiro», disponible en https://bit.ly/38oaF8B.

9. Ordenanza 1.129, de 13 de octubre de 2017, «Dispõe sobre os conceitos de trabalho forçado, jornada exaustiva e condições análogas à de escravo para fins de concessão de seguro-desemprego ao trabalhador que vier a ser resgatado em fiscalização do Ministério do Trabalho», disponible en https://bit. ly/3oKvhYh. 
debilitamiento de las normas de combate a la esclavitud contemporánea, sino también la comprensión sobre el agravamiento de la precariedad del trabajo que potencializa el problema de los explotados en condiciones análogas a la esclavitud, tanto en las zonas rurales como en las urbanas, al enfrentar directamente los principios constitucionales fundamentales de la dignidad de la persona humana y el valor social del trabajo.

La precariedad en la protección del trabajo no se limitó a los intentos de restringir el alcance conceptual del delito de trabajo análogo al de la esclavitud. Avanzó en dos mecanismos importantes: la subcontratación y una amplia reforma laboral, con el debilitamiento de las organizaciones sociales mediadas por los sindicatos. ${ }^{10}$

El 31 de marzo de 2017, tras un decreto del Congreso Nacional, el entonces presidente Michel Temer sancionó la Ley 13.429, con la intención de modificar bruscamente la normativa sobre la contratación externa. Dicha norma comenzó a permitir el uso de la subcontratación en cadena y para la prestación de cualquier tipo de servicio, descartando cualquier vínculo entre el trabajador y el tomador de los servicios en tales condiciones, sin establecer una obligación de igualdad de trato ante los demás trabajadores en cuestiones básicas como la atención médica, la atención ambulatoria y las comidas, además de eliminar el carácter solidario de la empresa que disfruta del trabajo por las cargas laborales y de seguridad social. En consecuencia, el trabajador es cada vez más vulnerable en el entorno laboral, ya que su vínculo con el tomador de los servicios comienza a ser bastante debilitado, lo que posibilita situaciones de trabajo degradante y con difícil capacidad de rendición de cuentas, debido a la protección legislativa, que va en contra de las pautas constitucionales.

Se agravó la situación abordada por la promulgación de la Ley 13.467 (reforma laboral), por el entonces presidente Michel Temer, con el debido apoyo del Congreso Nacional, el 13 de julio de 2017, que sacudió las bases protectoras constitucionales del derecho del trabajo. La prevalencia del acuerdo entre los sujetos de la producción ante la ley está ahora en vigor, según lo establecido en el artículo 611-A de la Consolidación de las Leyes Laborales, en varias situaciones, como: pacto sobre el horario de trabajo, teletrabajo, régimen de guardia, trabajo intermitente y el encuadramiento del grado de insalubridad, entre otros.

Ante esto, existe una clara medida que viola los derechos sociales protegidos por la Constitución, pero aprobada a través del procedimiento legal requerido, que fomenta la precarización del trabajo en diversos aspectos y culmina fatalmente en el incentivo a jornadas de trabajo exhaustivas y degradantes. Dallegrave Neto (2014) refuerza que las medidas que pretenden superar el estado de bienestar social empiezan a defender la desuniversalización de los derechos laborales y la atenuación abrupta del principio constitucional de protección de los empleados.

10. En 2015, en el Gobierno de Dilma Rousseff, se produjo la reforma de la pensión por fallecimiento. Véase Leite y Cabral (2017). 
En este ámbito, es importante destacar la flexibilización del marco del grado de insalubridad, que afecta directamente a las personas que se encuentran en situaciones vulnerables de trabajo degradante, al no atribuir el digno respeto a la salud física y sicológica de los trabajadores. Cabe mencionar la innovación regulada por la reforma laboral del instituto de trabajo intermitente, que se caracteriza por la legitimación de un contrato de trabajo que permite al trabajador no tener seguridad financiera, horas de trabajo diarias y otros derechos sociales.

Teniendo esto en cuenta, Streck ${ }^{11}$ advierte que el trabajo intermitente hace que los medios de contratación de trabajadores sean precarios, basándose en la falacia del aumento de los empleos en Brasil, destacando que el empleo precario no es el verdadero empleo, ya que la Constitución de 1988 no se limita a un enfoque cuantitativo de la generación de empleo, sino que la debida importancia al aspecto cualitativo de ese trabajo, que abarca los derechos subjetivos de los trabajadores enumerados en el artículo 7, como el salario mínimo y las vacaciones.

Por lo tanto, existe una laguna jurídica para la imposición de obras degradantes acompañadas de viajes exhaustivos sin ningún tipo de apoyo a los explotados, es decir, que permitan las condiciones de la esclavitud contemporánea con camuflaje legislativo.

Dentro del Poder Judicial también hay demostraciones del uso de las instituciones democráticas para reiterar los desacuerdos con las bases del constitucionalismo contemporáneo, sacrificando los derechos sociales que deberían ser protegidos. Un ejemplo de esto es el hecho de que, en 2015, Brasil fue el primer país en ser condenado por la Corte Interamericana de Derechos Humanos (CIDH) por su omisión en la lucha contra el trabajo esclavo. ${ }^{12}$ El caso en cuestión fue el decreto en que Brasil violó las garantías laborales de 85 trabajadores que fueron explotados en una granja en el estado de Pará en 2000. ${ }^{13}$

Después de dieciséis años del caso en el Poder Judicial brasileño, la CIDH determinó en una sentencia que «ninguno de los procedimientos legales en la sede interna determinó ningún tipo de responsabilidad, ni sirvió para obtener reparación para las víctimas o estudiar el asunto a fondo». Se mostró un verdadero desprecio por la preservación de las garantías fundamentales de los trabajadores previstas en la Constitución.

11. Lenio Luiz Streck, «Reforma trabalhista: Contrato intermitente é inconstitucional», Consultor Jurídico, 4 de diciembre de 2017, disponible en https://bit.ly/3hmdmUq.

12. Alvaro Murillo, «Brasil recebe a primeira condenação da CIDH por escravidão», El País, Brasil, 16 de diciembre de 2016, disponible en https://bit.ly/3mJu3Lo.

13. Inicialmente abordado en la Investigación Policial 2001.39.01.00270-o ante el Tribunal del Segundo Circuito de la Justicia Federal de Marabá y después convertido en el Procedimiento de Investigación Criminal 1.23.005.000177/2017-62. 
Los debates sobre la Lista Sucia también ponen de relieve las presiones políticas por la ineficacia de los fundamentos constitucionales que apoyan a la clase obrera. La Lista Sucia fue creada por la Ordenanza 540 del Ministerio de Trabajo y Empleo en octubre de 2004, y es una de las principales políticas públicas que tratan de combatir el trabajo esclavo contemporáneo, caracterizado por la publicación de los nombres de empresas o individuos que han sido condenados por la justicia, lo que permite el control estatal y público sobre tales prácticas repulsivas.

Según el Ministerio Público de Trabajo, la Lista Sucia tiene un efecto pedagógico y se actualiza cada seis meses. La divulgación de los nombres de los empleadores siempre es objeto de controversias en el Poder Judicial, lo que a menudo impide su divulgación. ${ }^{14}$ Para la abogada del Ministerio Público del Trabajo, Débora Tito:

La Lista Sucia impone pérdidas financieras y de imagen a las empresas, que buscaban precisamente abaratar sus costes de producción esclavizando a la mano de obra. La empresa pierde las inversiones y el derecho a la financiación pública. La Ordenanza 540 no obliga a los bancos a no financiar a los infractores, pero la repercusión social termina por tener efecto. ${ }^{15}$

La iniciativa de la Lista Sucia fue incluso mencionada en el Informe sobre la Trata de Personas de 2007 del Departamento de Estado de los Estados Unidos, con la intención de servir de ejemplo a otros países en la eficacia de la lucha contra el trabajo en condiciones de esclavitud. ${ }^{16}$ Sin embargo, las presiones políticas sobre la Lista Sucia tuvieron impactos más relevantes a partir de diciembre de 2014, cuando el juez Ricardo Lewandowski, del Supremo Tribunal Federal, suspendió la divulgación de la Lista Sucia mediante la aceptación de la solicitud de una asociación de promotores inmobiliarios que cuestionaba precisamente la constitucionalidad de esta política pública.

Este hecho ocurrió, como señala Borges (2015), incluso después de que el Ministerio Público Federal advirtiera que con esta posición el Tribunal estaría ejerciendo la ilegalidad del control abstracto de la constitucionalidad de los actos infralegales, según el estatuto de la Ordenanza abordado en la materia. Cabe señalar que esta suspensión duró cerca de un año y seis meses, momento en el que la ministra Carmen Lucía del Supremo Tribunal Federal emitió la Ordenanza 4, del 11 de mayo de 2016, en la que se destaca la constitucionalidad de la Lista Sucia y su importancia en la mejora del derecho al trabajo decente.

Sin embargo, el Ministerio de Trabajo y Empleo en ese momento, abusando de sus competencias, ignoró sus obligaciones y no publicó la Lista Sucia en 2016, lo que

\footnotetext{
14. Para una crítica del proceso de revisión judicial en el Brasil, véase Cabral (2014).

15. «Lista Suja», Em Discussão, 14 de julio de 2011, disponible en https://bit.ly/3mIJmDR.

16. «Trafficking in persons report: June 2007», United States Departament of State, disponible en https://bit.ly/3oOoIkA.
} 
provocó una acción civil pública del Ministerio Público de Trabajo para exigir dicha divulgación. El mandato judicial concedido en la acción civil fue revocado por el presidente del Tribunal Superior del Trabajo en marzo de 2017, liberando al Ministerio de la divulgación de la Lista Sucia. ${ }^{17}$ La revelación finalmente tuvo lugar el 10 de abril de 2018.

Las acciones del Poder Ejecutivo brasileño pueden insertarse en el contexto del constitucionalismo abusivo cuando el tema es el trabajo esclavo contemporáneo. Al hacer uso de sus facultades administrativas constitucionales para impedir una inspección efectiva para combatir las violaciones de los derechos sociales protegidos en la Constitución, el Gobierno amplió la protección de los trabajadores.

En 2017, por ejemplo, el presupuesto anual del impuesto sobre el trabajo del Ministerio de Trabajo y Empleo ya estaba comprometido en agosto. Según la encuesta de la Comisión Pastoral de la Tierra, hay una intensa disminución del ritmo de las inspecciones y, por consiguiente, del número de trabajadores rescatados en condiciones análogas a la esclavitud. ${ }^{18}$ Esta situación de abandono se debe a la constante disminución de los recursos destinados a la inspección de las condiciones de vida de los trabajadores.

La situación se agravó aún más con la elaboración de leyes que comprometen precariamente los derechos sociales, como la reforma laboral y la desregulación de los modelos de subcontratación, ambas en 2017. Además, el Ministerio de Trabajo y Empleo, un organismo que forma parte de las estrategias de inspección del trabajo esclavo, entre otras formas degradantes de explotación, se extinguió en 2019 en el Gobierno de Jair Bolsonaro (sin partido político).

Dicho esto, las políticas públicas destinadas a salvaguardar los derechos sociales están siendo cada vez más desechadas en la esfera administrativa, lo que caracteriza una verdadera falta de respeto por las directrices constitucionales e internacionales, sin necesidad de una ruptura repentina con las estructuras políticas.

Por lo tanto, las formas en que los poderes de la República tratan el trabajo esclavo contemporáneo en Brasil reflejan el panorama de un constitucionalismo abusivo con grandes repercusiones en los compromisos internacionales y en el propio derecho interno. Cabe destacar que este proceso se desarrolla de manera indirecta, ya que los ataques se dirigen sobre todo contra normas infraconstitucionales, lo que sacude los parámetros constitucionales de manera incidental al restringir la efectividad de los derechos sociales garantizados. Sin embargo, esta sutileza agrava la preocupación por la cuestión, ya que incluso frente al mantenimiento de la estructura jurídica constitu-

17. Heloísa Mendonça, «Governo barra outra vez a divulgação da 'lista suja' do trabalho escravo no Brasil», El País, Brasil, 12 de marzo de 2017, disponible en https://bit.ly/2TIJLts.

18. Karina Trevizan y Vitor Sorano, «Fiscalização do trabalho escravo cai e verba do setor termina em agosto, dizem entidade e sindicato», Globo, 25 de julio de 2017, disponible en https://glo.bo/3hoeV4r. 
cional de protección de los derechos sociales, hay constantes iniciativas que indican violaciones de la protección de la dignidad de los trabajadores, a través de competencias descritas por la propia Constitución, lo cual agrava la coyuntura brasileña de lucha contra el trabajo esclavo.

\section{Conclusión}

Este artículo analizó el riesgo de constitucionalismo abusivo en Brasil a través de reflexiones sobre las formas en que los poderes de la República tratan el trabajo esclavo contemporáneo que, entre disputas conceptuales, radicalizan la situación brasileña.

Inicialmente se demostró que el derecho al trabajo decente es uno de los fundamentos del constitucionalismo contemporáneo, porque indica la superación de un dogma tradicional que agravaba las desigualdades sociales y despreciaba la dignidad humana. Dicho esto, el trabajo es visto ahora como un instrumento de realización individual y el foco de las garantías sociales protegidas por la Constitución.

Luego, se presentó el concepto de constitucionalismo abusivo, indicando que las estructuras legales no deben ocuparse exclusivamente de los golpes políticos que rompen en forma abrupta el sistema actual, ya que existen formas más sutiles, pero no menos peligrosas, de violar la Constitución a través de los instrumentos constitucionales. En el escenario brasileño, destacan las propuestas de enmiendas constitucionales después del proceso de destitución de la presidenta Dilma Rousseff, que afectan a las garantías sociales previstas en la propia Constitución. Tales medidas comenzaron a restringir las inversiones públicas capaces de estipular acciones afirmativas que alivian las dificultades de los brasileños en cuanto a sus derechos básicos, además de enfrentar, de manera más contundente, el bienestar de los trabajadores.

Por último, se observa que la forma en que se trata el trabajo esclavo contemporáneo en Brasil justifica su encuadramiento en países que sufren de un constitucionalismo episódico abusivo indirecto, en especial en lo que respecta a la falta de respeto de las garantías sociales de los trabajadores más vulnerables que están protegidos por directrices constitucionales.

Esta coyuntura es visualizada por la tendencia política, respecto del problema que implica la esclavitud contemporánea, ya sea en su concepto o en sus causas sociales, de no confrontar el texto expreso de la Constitución ni proponer ningún aditivo constitucional que contradiga directamente lo ya establecido. La estrategia adoptada sacude las normas infraconstitucionales específicas sobre las relaciones laborales y el propio concepto de sumisión a condiciones análogas a la esclavitud a través de la proposición de leyes, reformas legislativas, ordenanzas y actos administrativos que debilitan la ejecución de las normas ya establecidas.

Este movimiento político fomenta la precariedad de las relaciones laborales, lo que impulsa la vulnerabilidad social, que es la principal causa del crecimiento de la 
esclavitud contemporánea. Además, enfrenta el concepto mismo de trabajo análogo al de la esclavitud, previsto en el Código Penal, para restringirlo al criterio de libertad de ir y venir, a los moldes de la época de la esclavitud legal.

Por último, todo este proceso se desarrolla mediante trucos legales, que no violan las pautas del sistema jurídico desde el punto de vista formal, pero violan de manera abrupta la esencia humanitaria de la Constitución que protege los derechos sociales de los trabajadores.

\section{Referencias}

BARboza, Estefânia Maria Queiroz e Ilton Norberto Robl Filho (2018) Constitucionalismo abusivo: Fundamentos teóricos e análise da sua utilização no Brasil contemporâneo. Belo Horizonte: Direitos Fundamentais \& Justiça.

Borges, Paulo César Corrêa (2015). «Panaroma da legislação de combate ao trabalho escravo na América do Sul». En Paulo César Correa Borges (coordinador), Formas contemporânea de trabalho escravo (pp. 25-56). São Paulo: Cultura Acadêmica Editora.

CABRAL, Rafael Lamera (2014). «Democracia, judiciário e a crítica à judicial review». Revista Direito e Liberdade, 16 (2): 187-210. Disponible en https://bit.ly/2WQou2I.

Carvalho Netto, Menelick de (2001). «Controle de constitucionalidade e democracia». En Antonio G. Moreira Maues (coordinador). Constituição e democracia (pp. 215-232). São Paulo: Max Limonad.

Da Silva, José Afonso (1992). Curso de direito constitucional positivo. São Paulo: Malheiros.

Dallegrave Neto, José Affonso (2014). «Prevalência do negociado sobre o legislado e a nova proposta de acordo coletivo especial». Revista Magister de Direito do Trabalho, 60: 15 .

Delgado, Gabriela Neves y Lara Parreira de Faria Borges (2015). «A revisitação do princípio da proteção pelo discurso constitucional trabalhista no Tribunal Superior do Trabalho». En Gabriela Neves Delgado, José Roberto Freire Pimenta, Luiz Philippe Vieira de Mello Filho y Othon de Azevedo Lopes (coordinadores), Direito constitucional do trabalho: Princípios e jurisdição constitucional do TST. São Paulo: LTr.

Delgado, Maurício Godinho (2017). Curso de direito do trabalho. São Paulo: LTr.

Delgado, Maurício Godinho y Gabriela Neves Delgado (2012). Constituição da República e Direitos Fundamentais: Dignidade da pessoa humana, justiça social e direito do trabalho. São Paulo: Ltr.

-. (2018). A reforma trabalhista no Brasil: com os comentários à Lei 13.467/2017. São Paulo: LTr. 
Fachin, Luiz Edson (2013). «Uns nos outros». En Thiago Ferreira Cardoso Neves (coordinador), Direito e justiça social por uma sociedade mais justa, livre e solidária: Estudos em homenagem ao professor Sylvio Capanema de Souza. São Paulo: Atlas.

Fioravanti, Maurizio (2001). Constitución: De la Antigüedad a nuestros días. Madrid: Trotta.

FrançA, Carlos Eduardo y Rafael Lamera Cabral (2016). «Direitos sociais e identidade operária: O poder da ideologia trabalhista no governo de Getúlio Vargas (Brasil, 1930-45)». Revista Eletrônica do Curso de Direito da UFSM, Santa Maria, 11 (2): 634-653. DOI: 10.5902/1981369421961.

Gomes, Angela de Castro y Regina Beatriz Guimarães Neto (2018). Trabalho escravo contemporâneo: Tempo presente e usos do passado. Río de Janeiro: FGV.

JARA Bustos, Francisco (2016). «La esclavitud y el trabajo forzado como crímenes de lesa humanidade». Revista Chilena de Derecho del Trabajo y de la Seguridad Social, 6 (12): 114-136. DOI: 10.5354/0719-7551.2016.38451.

LANDAU, David (2020). «Constitucionalismo abusivo». Revista Jurídica da UFERSAREJUR, 4 (7): 17-71.

Leite, Ana Adrielle Bertini Pinto de Castro y Rafael Lamera Giesta Cabral (2017). «Em tempos de crise, novos ajustes: Uma breve análise sobre a reforma do benefício de pensão por morte (2015-2016)». Revista do Curso de Direito UNIFOR-MG, 8 (2): 130-167. DOI: $10.24862 /$ rcdu.v8i2.712.

Machado, Luiz (2017). "O Instrumental Internacional da OIT e a Prospecção do Combate ao Trabalho Forçado». En Cristiano Paixão y Tiago Muniz Cavalcanti (coordinadores), Combate ao trabalho escravo: Conquistas, estratégias e desafios (pp. 200-210). São Paulo: Ltr.

Saldanha, Nelson (200o). Formação da teoria constitucional. Río de Janeiro: Renovar.

SiqueIra, Elisabete Stradiotto, Valéria Rueda Elias Spers y Lucas Andrade de Morais (2019). «Direito humano ao trabalho e políticas públicas de inclusão sociolaboral no Brasil». Revista Jurídica da UFERSA-REJUR, 3 (6): 140-157. DOI: 10.21708/ issn2526-9488.v3.n6.p140-157.2019.

Sobrinho, Cicero José, Evandro da Silva Barros y Heitor Romero Marques (2014). Bolivianos e paraguaios: O trabalho escravo de imigrantes em Campo Grande e o posicionamento do estado de Mato Grosso do Sul frente à rota do tráfico de pessoas. Campo Grande: UCDB.

Souto MaIor, Jorge Luiz (2017). História do direito do trabalho no Brasil: Curso de direito do trabalho. São Paulo: LTr.

Tushnet, Mark (2013). «Authoritarian constitutionalism: Some conceptual issues». En Tom Ginsburg y Alberto Simpser (editores), Constitutions in authoritarian regimes. Cambridge: Cambridge University Press. 
VIlela, Ruth (2006). Depoimento concedido ao projeto história do Ministério do Trabalho e Emprego. Río de Janeiro: CDPOC/FGV.

\section{Sobre los autores}

Rafael Lamera Giesta Cabral es abogado. Doctor en Derecho, Estado y Constitución por la Universidad de Brasilia, Brasil. Magíster en Ciencias Políticas de la Universidad Federal de São Carlos, Brasil y licenciado en Derecho de la Universidad Estatal de Mato Grosso do Sul, Brasil. Profesor adjunto de la carrera de Derecho, coordinador del programa de Posgrado en Derecho Stricto Sensu (Maestría Académica) y profesor del programa de Posgrado en Administración Pública (Maestría Profesional PROFIAP) de la Universidad Federal Rural del Semiárido, Brasil. Su correo electrónico es rafaelcabral@ufersa.edu.br. (1D) http://orcid.org/oooo-0002-6442-4924.

Iury Alves de Sousa es abogado. Magíster en Derecho de la Universidad Federal del Semiárido, Brasil. Especialista en derecho civil y procesal civil del Centro Universitario de Patos, Brasil. Su correo electrónico es iuryalveso16@gmail.com. (D) http:// orcid.org/oooo-0002-3590-7732. 
La Revista Chilena de Derecho del Trabajo y de la Seguridad Social es una publicación semestral del Departamento de Derecho del Trabajo y de la Seguridad Social de la Facultad de Derecho de la Universidad de Chile, y que tiene por objetivo el análisis dogmático y científico de las instituciones jurídico-laborales y de seguridad social tanto nacionales como del derecho comparado y sus principales efectos en las sociedades en las que rigen.

\author{
DIRECTOR \\ Luis Lizama Portal \\ EDITOR \\ Claudio Palavecino Cáceres \\ SECRETARIO DE REDACCIÓN \\ Eduardo Yañez Monje \\ SITIO WEB \\ revistatrabajo.uchile.cl \\ CORREO ELECTRÓNICO \\ pyanez@derecho.uchile.cl \\ LICENCIA DE ESTE ARTÍCULO \\ Creative Commons Atribución Compartir Igual 4.o Internacional
}

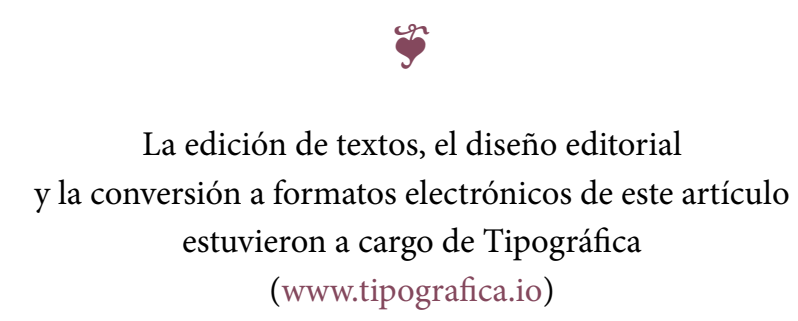

